\title{
Varicella Zoster Infection in Renal Transplant Recipients: Prevalence, Complications and Outcome
}

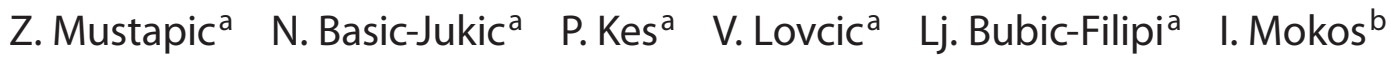 \\ Z. Kastelan ${ }^{\text {b }}$ S. Zekan ${ }^{c}$ \\ Departments of a Nephrology, Arterial Hypertension and Dialysis, and ${ }^{b}$ Urology, Clinical Hospital \\ Centre Zagreb and School of Medicine, University of Zagreb, and ${ }^{C} \mathrm{Clinical}$ Hospital for Infectious Diseases \\ 'Fran Mihaljevic', Zagreb, Croatia
}

\section{Key Words}

Renal transplantation $\cdot$ Immunosuppression • Varicella zoster $\cdot$ Mycophenolate mofetil $\cdot$ Varicella zoster virus infection

\begin{abstract}
Varicella zoster virus (VZV) is an important pathogen after renal transplantation. In the present study, we examined the prevalence, clinical presentation and outcome of VZV infections in renal transplant recipients. Charts and medical records of adult renal allotransplant recipients were investigated to find patients with VZV infection. From December 1972 until July 2010, 1,139 patients received kidney allograft at our institution. VZV infection was diagnosed in 40 patients (3.51\%). 28 patients (70\%) had intensified immunosuppression prior to VZV infection occurrence. Median time of onset was 2.13 years after transplantation (range 9 days to 19.2 years). 35 patients developed VZV during the first post-transplant year (median 0.61 years). Four patients developed VZV infection more than 12 years after transplantation. 33 patients $(82.5 \%)$ had dermatomal distribution, 5 (12.5\%) disseminated herpes zoster $(\mathrm{HZ})$, and 2 patients $(5 \%)$ who were VZV IgG-negative before transplantation, developed chick-
\end{abstract}

enpox. Immunosuppression was reduced and patients received acyclovir. Cutaneous scarring was recorded in 7 cases (17.5\%). Two patients developed post-herpetic neuralgia, which was accompanied by scarring and skin depigmentation in 1 of them. Five patients (12.5\%) experienced relapse of HZ. Timely initiation of therapy may prevent development of complications and the visceral form of disease. Based on our experience with development of chickenpox, we suggest active immunization for all seronegative patients before organ transplantation.

Copyright $\odot 2011$ S. Karger AG, Basel

\section{Introduction}

An individual risk for development of infection after renal transplantation is determined by a relationship between the epidemiologic exposure of the individual and the state of immunosuppression which determines the individual's susceptibility to infection [1].

Varicella zoster virus (VZV) is an important pathogen in organ transplant recipients $[2,3]$. VZV infection causes two clinically different forms of disease: primary disease (varicella or chickenpox) is characterized by ve-

\section{KARGER}

Fax +4161306 1234 E-Mail karger@karger.ch www.karger.com

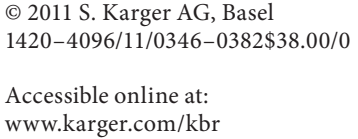

Nikolina Basic-Jukic, MD, PhD

Department of Nephrology, Arterial Hypertension and Dialysis

Clinical Hospital Centre Zagreb

Kispaticeva 12, HR-10000 Zagreb (Croatia)

Tel. +385 12312 517, E-Mail nina_basic@ @et.hr 
sicular lesions on the trunk, head or extremities, and herpes zoster (HZ) (shingles) is characterized by a painful unilateral vesicular eruption, which may rarely be disseminated.

In the present study, we examined the prevalence, clinical presentation and outcome of VZV infections in renal transplant recipients.

\section{Patients and Methods}

Charts and medical records of adult renal allotransplant recipients transplanted between December 1972 and July 2010 were investigated to find patients with VZV infection.

The immunosuppressive protocols included antiproliferative drugs, steroids and, from 1989, cyclosporin A (CyA). Before 2002 we used only azathioprine (AZA) as an antiproliferative drug, and since that time mycophenolate mofetil (MMF) has replaced AZA in immunosuppressive protocols in our center. Steroid dose at transplant was $0.5 \mathrm{mg} / \mathrm{kg} / \mathrm{day}$, which was tapered toward the maintenance dose of $0.05 \mathrm{mg} / \mathrm{kg} /$ day. From 2005, tacrolimus was introduced beside CyA. From the year 2004, patients with more than three mismatches received induction therapy with basiliximab or daclizumab, and until that time this group was treated with a steroid bolus $(500 \mathrm{mg}$ ) prior to transplantation. While HLA matching was crucial for organ allocation until 2007 when we joined Eurotransplant, induction treatment was rarely used (18.4\% of all patients).

Rejection episodes were treated with steroids $(10 \mathrm{mg} / \mathrm{kg})$, which had been given in 3-5 boluses. From the introduction of ganciclovir in 1999 in our center, all CMV IgG-negative patients who received an allograft from a CMV IgG-positive donor were treated with antiviral prophylaxis for 3 months (21 days intravenously, followed by oral ganciclovir).

Age, gender, time on dialysis, time of transplantation, immunosuppressive protocol, viral status before transplantation, episodes of acute graft rejection, other viral infections, and graft function were recorded. Detailed clinical characteristics of VZV infection were noted (localization, dissemination, complications and outcome).

The diagnosis was made on clinical grounds and/or VZV seroconversion. The study was approved by the Ethics Committee of the School of Medicine, University of Zagreb. We used descriptive statistics (Microsoft Office, Excel 2007).

\section{Results}

\section{Patients' Characteristics}

From December 1972 until July 2010, 1,139 patients (58.7\% male) received a kidney allograft at our institution. Mean age at transplantation was 52 years, with the dialysis vintage distribution from the preemptive transplantation to 25 years.

VZV Infection in Renal Transplant Recipients
Table 1. Clinical characteristics of patients with VZV infection

$\begin{array}{ll}\text { Patients } & 40 \\ \text { Male gender } & 67.5 \% \\ \text { Mean age (range) } & 51.8(28-69) \\ \text { VZV IgG-negative before transplantation } & 2 \\ \text { Induction } & 27.5 \% \\ \text { MMF vs. AZA } & 38 \mathrm{vs.} 2 \\ \text { CyA vs. tacrolimus } & 38 \text { vs. } 2 \\ \text { Mean onset of VZV after transplantation } & 2.13 \text { (9 days- } \\ \quad \text { years (range) } & 19.2 \text { years) } \\ \text { Intensified immunosuppression } & 70 \% \\ \text { Localized vs. disseminated } & 33 \text { vs. } 5 \\ \text { Chickenpox } & 2 \\ \text { Treatment, peroral vs. intravenous } & 34 \text { vs. } 6 \\ \text { Complications } & \\ \quad \text { Neuropathy } & 2 \\ \text { Cutaneous scarring } & 7 \\ \text { Relapses } & 5\end{array}$

Data are presented as numbers of patients unless otherwise indicated. $\mathrm{VZV}=$ Varicella zoster; $\mathrm{MMF}=$ mycophenolate mofetil; $\mathrm{AZA}=$ azathioprine; $\mathrm{CyA}=$ cyclosporin $\mathrm{A}$.

VZV infection was diagnosed in 40 patients (3.51\%). There were 27 male patients and 13 female patients, with the mean age at diagnosis of 51.8 years (table 1). 39 of them received a renal transplant from a deceased donor. Average time on dialysis was 6.8 years.

At the time of onset, 36 patients had CyA, MMF and steroids, 2 had tacrolimus, MMF and steroids, and 2 AZA and CyA in therapy. The mean CyA concentration was $157.5 \mu \mathrm{mol} / \mathrm{l}$ (range 85-294) and the mean dose of MMF was $916 \mathrm{mg} / \mathrm{m}^{2}$ (range 300-1,260) at the time of VZV infection. Mycophenolic acid concentration was not determined. Two patients receiving tacrolimus had a serum concentration of 12.9 and $13.6 \mathrm{ng} / \mathrm{ml}$, and 7 patients had $\mathrm{CyA} \mathrm{C}_{0}>200 \mu \mathrm{mol} / \mathrm{l}$. Eleven patients (27.5\%) received induction therapy with basiliximab or daclizumab in their immunosuppressive protocol. Ten patients (25\%), 2 of whom received induction therapy, had acute graft rejection and were treated with 3 ( 2 patients) to 5 (8 patients) boluses of intravenous methylprednisolone 3 weeks to 3 months prior to VZV reactivation. The average dose of methylprednisolone for rejection therapy was $2,875 \mathrm{mg}$. Thus, 28 patients (70\%) had enhanced immunosuppression prior to VZV infection.

Six patients (15\%) received antiviral treatment before development of VZV infection, due to CMV infection, and 3 patients received ganciclovir prophylaxis for CMV mismatches, 2-4 months before VZV infection. Three

Kidney Blood Press Res 2011;34:382-386 

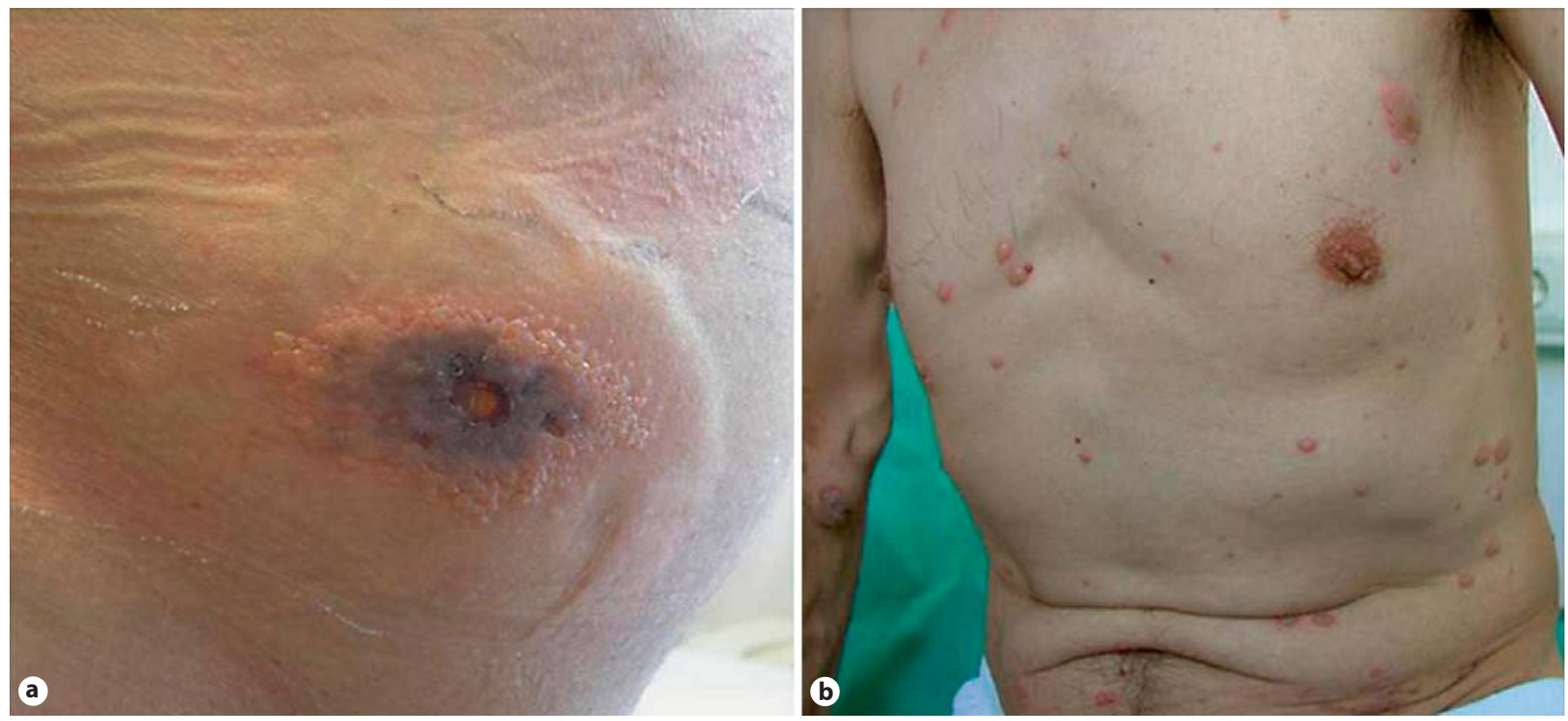

Fig. 1. a Severe form of localized HZ with central necrosis. b Disseminated HZ.

patients had chronic hepatitis $\mathrm{C}$ infection. One patient had chronic hepatitis B infection, and 1 patient had positive BK virus in urine. We had no HIV-positive patients (table 1).

\section{Timing of VZV Infection}

Median time of onset was 2.13 years after transplantation (range 9 days to 19.2 years). 35 patients (85\%) developed VZV during the first post-transplant year (median 0.61 years). Four patients (10\%) developed VZV infection a long time after transplantation (10.3, 15.8, 17.2 and 19.2 years after transplantation, respectively). Two of these patients had received AZA since transplantation, while in 2 patients AZA was replaced with MMF after acute graft rejection, 3.7 and 7.8 years prior to VZV infection, respectively. None of the patients treated with AZA developed disseminated disease.

\section{Clinical Presentation of VZV Infection}

33 patients $(82.5 \%)$ had dermatomal distribution, 5 (12.5\%) disseminated $\mathrm{HZ}$, and 2 patients (5\%) who were VZV IgG-negative before transplantation developed chickenpox. Severe skin changes were recorded (fig. la). Two patients who received an organ from the same donor developed VZV infection 29 days after transplantation. The donor was VZV IgG-positive, IgM-negative. One recipient was VZV IgG-positive and developed disseminat- ed vesicular rash (fig. 1b), and another was VZV IgGnegative (he developed chickenpox). There was no known exposure to the virus in the other patients.

Deterioration of graft function was recorded in $1 \mathrm{pa}-$ tient, and 2 had transient elevation of liver enzymes.

\section{Treatment of VZV infection}

In the treatment of VZV infection, 33 patients (82.5\%) received acyclovir orally, 6 (15\%) acyclovir intravenously and $1(2.5 \%)$ had no antiviral treatment because he failed to visit a doctor. Antiviral therapy was introduced $0-3$ days after vesicular eruption. Patients received $5 \times$ $800 \mathrm{mg}$ of acyclovir for 7-10 days (doses were adjusted for graft function if necessary). Seven (17.5\%) patients had no changes in immunosuppressive treatment (they were treated in local hospitals). MMF was reduced in 28, and temporarily switched off in 5 patients. CyA and tacrolimus were reduced in patients with elevated $\mathrm{C}_{0}$ concentrations. Steroid dose was decreased in 6 patients. Steroids were tapered off in 2 patients (those with the relapsing form of disease, previous CMV and/or BK infection).

\section{Complications and Outcome}

All patients and grafts survived. Complications occurred in 9 patients (22.5\%). Cutaneous scarring was recorded in 7 cases (17.5\%). Two patients (5\%) developed 
post-herpetic neuralgia (PHN), which was accompanied by scarring and skin depigmentation in 1 of them.

Five patients (12.5\%) experienced relapse of HZ. In 2 of them with three or more relapses, immunosuppression was changed, and AZA was introduced instead of MMF. Two patients had already experienced two episodes of VZV infection before transplantation each. A female patient had been treated for CMV infection, and a male patient had positive BK virus in urine determined by PCR. Only 1 of the patients who relapsed had received five boluses of steroids 2 months before development of the first episode of VZV infection.

\section{Discussion}

VZV infection is a rare but potentially serious complication in renal transplant recipients. Lethal outcomes of VZV infection have been recorded [2, 4]. Our results demonstrated a relatively low prevalence of VZV infection in renal transplant recipients (3.51\%), compared with other studies which recorded a prevalence of 3-10\% $[5,6]$. Female gender is considered as risk factor for developing $\mathrm{HZ}$ in liver transplant recipients, while in the renal transplant population $63 \%$ of patients who developed VZV infection were male [5]. In our cohort, $67.5 \%$ of patients were male.

The frequency and intensity of VZV infection is associated with the intensity of immunosuppression $[7,8]$. Introduction of MMF in an immunosuppressive protocol improved graft survival $[9,10]$. However, an increased incidence of different viral infections was recorded [1116]. According to our results, introduction of MMF in an immunosuppressive protocol resulted in a higher incidence and more severe VZV disease. All our patients with disseminated disease were in the MMF era. Early therapy with acyclovir orally with a reduction of MMF dose is a therapy of choice. We believe that dose adjustment and finding an upper limit of the therapeutic range of mycophenolic acid, above which the risk of different viral infection is increased, needs to be determined for MMF therapy in the following studies [17], at least in patients who received enhanced immunosuppression early in the post-transplant period. Seventy percent of patients were exposed to intensive immunosuppressive treatment before VZV infection, while they received either an induction or steroid bolus therapy for treatment of acute rejection, or had a high calcineurin inhibitor concentration. This is in line with the previous observations that intensive immunosuppression presents a risk factor for development of VZV infection $[1,8]$.

VZV Infection in Renal Transplant Recipients
The majority of our patients developed VZV infection during the first post-transplant year. Only 4 patients experienced disease a long time after transplantation, thus prolonging the median time of onset (2.13 years). Previous studies reported the onset of VZV infection after solid organ transplantation to be between 2 and 92 months $[3,5,18]$. Switch from AZA to MMF resulted in more intensive immunosuppression and subsequently in development of VZV infection in 2 of our patients (up to 228 months after transplantation).

Five cases of disseminated $\mathrm{HZ}$ were recorded, which is a relatively high proportion in comparison with other studies (fewer than 40 cases described in the literature). A mortality rate of $34 \%$ was described in patients with disseminated HZ [2]. None of our patients died, probably because of the fast recognition and initiation of antiviral therapy. However, in immunocompromised patients, visceral dissemination of VZV may occur without skin eruptions $[19,20]$ rendering diagnosis difficult and prolonging the time to initiation of antiviral therapy. A lethal case of VZV infection has been reported without skin lesions [21, 22]. Keeping in mind the retrospective design of our study, it may be possible that such cases have been missed and the risk of VZV infection might be underestimated.

We report a low rate of PHN (5\%) in our patients, but a relatively high rate of cutaneous scarring (17.5\%). Other authors reported PHN in up to $42.7 \%$ of solid organ recipients $[5,23]$.

Active immunization for VZV-seronegative patients before transplantation should be performed. Taking into account that cellular immunity in patients with end-stage renal disease is impaired and results of vaccination against hepatitis B are suboptimal [24, 25], it may be suspected that vaccination against VZV in patients awaiting renal transplantation may be of limited efficacy. However, vaccination should be recommended to all seronegative patients in order to try to decrease the incidence of this potentially fatal post-transplant complication.

High-dose acyclovir therapy together with reduction of immunosuppression is a cornerstone of VZV infection treatment. Timely initiation of therapy may prevent development of complications and the visceral form of disease. Based on our experience with the development of chickenpox, we suggest active immunization for all seronegative patients before organ transplantation.

Kidney Blood Press Res 2011;34:382-386 


\section{References}

1 Fishman JA: Infection in renal transplant recipients. Semin Nephrol 2007;27:445-461.

$\checkmark 2$ Fehr T, Bossart W, Wahl C, Binswanger U: Disseminated varicella infection in adult renal allograft recipients: four cases and a review of the literature. Transplantation 2002; 73:608-611

-3 Rodriguez-Moreno A, Sanchez-Fructuoso AI, Calvo N, Ridao N, Conesa J, Marques M, Prats D, Barrientos A: Varicella infection in adult renal allograft recipients: experience at one center. Transplant Proc 2006;38:24162418.

4 Lauzurica R, Bayés B, Frías C, Fontseré N, Hernandez A, Matas L, Jimenez A, Bonet J, Romero R: Disseminated varicella infection in adult renal allograft recipients: role of mycophenolate mofetil. Transplant Proc 2003; 35:1758-1759.

5 Gourishankar S, McDermid JC, Jhangri GS, Preiksaitis JK: Herpes zoster infection following solid organ transplantation: incidence, risk factors and outcomes in the current immunosuppressive era. Am J Transplant 2004;4:108-115.

6 Miller GG, Dummer JS: Herpes simplex and varicella zoster viruses: forgotten but not gone. Am J Transplant 2007;7:741-747.

$\checkmark 7$ Arness T, Pedersen R, Dierkhising R, Kremers W, Patel R: Varicella zoster virus-associated disease in adult kidney transplant recipients: incidence and risk-factor analysis. Transpl Infect Dis 2008;10:260-268.

$\checkmark 8$ Fishman JA: Infection in solid-organ transplant recipients. N Engl J Med 2007;57:26012614.

\$9 The Tricontinental Mycophenolate Mofetil Renal Transplantation Study Group: A blinded, randomized clinical trial of mycophenolate mofetil for the prevention of acute rejection in cadaveric renal transplantation. Transplantation 1996;61:1029-1037.
10 European Mycophenolate Mofetil Cooperative Study Group: Placebo-controlled study of mycophenolate mofetil combined with cyclosporin and corticosteroids for prevention of acute rejection. Lancet 1995;345:13211325.

11 Basic-Jukic N, Kes P, Bubic-Filipi LJ, Puretic Z, Brunetta B, Pasini J: Does mycophenolate mofetil increase the incidence of cytomegalovirus disease compared with azathioprine after cadaveric kidney transplantation? Transplant Proc 2005;37:850-851.

12 Basic-Jukic N, Racki S, Kes P, Mustapic Z: Cytomegalovirus infection in renal transplant recipients (in Croatian). Acta Med Croatica $2008 ; 62: 69-75$.

13 Marcén R: Immunosuppressive drugs in kidney transplantation: impact on patient survival, and incidence of cardiovascular disease, malignancy and infection. Drugs 2009;69:2227-2243.

14 Satoh S, Tada H, Murakami M, Tsuchiya N Inoue $\mathrm{T}$, Togashi $\mathrm{H}$, Matsuura S, Hayase $\mathrm{Y}$, Suzuki T, Habuchi T: The influence of mycophenolate mofetil versus azathioprine and mycophenolic acid pharmacokinetics on the incidence of acute rejection and infectious complications after renal transplantation. Transplant Proc 2005;37:1751-1753.

15 Rothwell WS, Gloor JM, Morgenstern BZ, Milliner DS: Disseminated varicella infection in pediatric renal transplant recipients treated with mycophenolate mofetil. Transplantation 1999;68:158-161.

16 Buell C, Koo J: Long-term safety of mycophenolate mofetil and cyclosporine: a review. J Drugs Dermatol 2008;7:741-748.

17 Cox VC, Ensom MH: Mycophenolate mofetil for solid organ transplantation: does the evidence support the need for clinical pharmacokinetic monitoring? Ther Drug Monit 2003;25:137-157.
18 Gnann JW: Other herpesviruses: herpes simplex virus, varicella-zoster virus, human herpes types 6,7 and 8; in Transplant Infections, ed 1. Philadelphia, Lippincott-Raven, 1998, pp 265-286.

19 Gilden D, Cohrs RJ, Mahalingam R, Nagel MA: Varicella zoster virus vasculopathies: diverse clinical manifestations, laboratory features, pathogenesis, and treatment. Lancet Neurol 2009;8:731-740.

20 Rogers SY, Irving W, Harris A, Russell NH: Visceral varicella zoster infection after bone marrow transplantation without skin involvement and the use of PCR for diagnosis. Bone Marrow Transplant 1995; 15:805-807.

-21 Jantsch J, Schmidt B, Bardutzky J, Bogdan C, Eckardt KU, Raff U: Lethal varicella-zoster virus reactivation without skin lesions following renal transplantation. Nephrol Dial Transplant 2011;26:365-368

$>22$ Peterson LR, Ferguson RM: Fatal central nervous system infection with varicellazoster virus in renal transplant recipients. Transplantation 1984;37:366-368.

23 Herrero JI, Quiroga J, Sangro B, Pardo F, Rotellar F, Alvarez-Cienfuegos J, Prieto J: Herpes zoster after liver transplantation: incidence, risk factors, and complications. Liver Transpl 2004;10:1140-1143.

24 Litjens NH, Huisman M, Baan CC, van Druningen CJ, Betjes MG: Hepatitis B vaccine-specific CD4+ T cells can be detected and characterised at the single cell level: limited usefulness of dendritic cells as signal enhancers. J Immunol Methods 2008;330:1-11.

25 Crosnier J: Hepatitis B in haemodialysis: vaccination against HBS antigen. Proc Eur Dial Transplant Assoc 1981;18:231-240. 